\title{
Cidades Médias e Sustentabilidade Ambiental: Caracterização e Atuação Regional
}

Karla de Souza Oliveira ${ }^{1}$; Francisco Itami Campos $^{2}$; Giovana Galvão Tavares ${ }^{3}$; Rildo Mourão Ferreira ${ }^{4}$

\section{RESUMO}

Este artigo pretende discutir as cidades médias sob a ótica da sustentabilidade ambiental, discorrendo acerca da função social da cidade e como sua aplicação carece de uma firme política urbana. Expõe considerações sobre as cidades médias, destacando suas singularidades em relação às metrópoles e às cidades pequenas. Conceitua-se desenvolvimento sustentável, localizando-o no Estatuto da Cidade para vislumbrar a chamada cidade sustentável. Busca aplicar o modelo proposto nos municípios de Rio Verde e Anápolis. A metodologia empregada, de natureza bibliográfica, sendo o método adotado o comparativo, analisando dados relativos aos municípios goianos, obtidos junto ao Instituto Brasileiro de Geografia e Estatística/IBGE, o Instituto Mauro Borges e respectivas prefeituras municipais. Os municípios escolhidos são cidades médias que precisam adotar ações mais pontuais para serem consideradas sustentáveis, tais como, aprimorando o saneamento básico, a coleta seletiva de resíduos sólidos, e outras opções sustentáveis de desenvolvimento urbano.

Palavras-Chave: Cidades médias; Sustentabilidade; Política Urbana.

\footnotetext{
1 Mestranda em Ciências Ambientais no Centro Universitário de Anápolis. Especialista em Ciências Penais pela UNIDERP e em Direito Constitucional pela Universidade Federal de Goiás - UFG. Centro Universitário de Anápolis, UniEVANGÉLICA, Brasil. ksoliveira.adv@gmail.com

2 Doutorado em Ciência Política pela Universidade de São Paulo, USP, Brasil. Docente no Centro Universitário de Anápolis, UniEVANGÉLICA, Brasil. itamicampos@gmail.com

${ }^{3}$ Doutora em Ciências pela Universidade Estadual de Campinas. Docente no Centro Universitário de Anápolis UniEVANGÉLICA, Brasil. gio.tavares@gmail.com

${ }^{4}$ Doutor em Ciências Sociais pela Pontifícia Universidade Católica de São Paulo - PUC/SP. Docente na Universidade de Rio Verde - FESURV e no Centro Universitário de Anápolis - UniEVANGELICA. rildomourao@uol.com.br
} 


\section{INTRODUÇÃO}

Com o crescimento das cidades, diversos são os problemas urbanos que surgem. Dentre estes problemas, os de maior destaque são a sustentabilidade ambiental, em razão da falta de estruturação e planejamento para seu desenvolvimento; a instalação de indústrias e a expansão do comércio; bem como os impactos ambientais decorrentes do agronegócio. Esses problemas carecem de soluções urgentes. E é importante tarefa fazer com que a sociedade e o Poder Público compreendam que as cidades não são apenas espaços onde se evidenciam problemas sociais e que a problemática ambiental está diretamente ligada às construções humanas e relações sociais, sejam por fatores físicos, econômicos, históricos ou culturais.

Para a construção de um espaço urbano de melhor qualidade e que favoreça a convivência dos cidadãos, é necessário que haja a implementação de políticas urbanas com soluções para os problemas ambientais nas cidades, decorrentes de seu desordenado crescimento. Dessa forma, buscou-se, por meio da promulgação do Estatuto da Cidade, solucionar esse impasse fixando diretrizes e instrumentos direcionados ao equilíbrio do crescimento das cidades e da preservação do meio ambiente para a melhor qualidade de vida das presentes e futuras gerações.

Para a realização da pesquisa, tornou-se pertinente o estudo de legislação, revisão bibliográfica de livros, artigos, teses e dissertações, para identificar os critérios utilizados na definição de uma cidade como média e sustentável. A partir da construção destes critérios, adotou-se o método comparativo envolvendo os municípios de Anápolis e Rio Verde, situados no estado de Goiás, utilizando dados provenientes de fontes como o Instituto Brasileiro de Geografia e Estatística (IBGE) e Instituto Mauro Borges (IMB), também recorrendo às informações coletadas nas Prefeituras das respectivas, para a caracterização de cidade como média e sustentável.

Dessa forma, esta pesquisa trabalha a análise dos conceitos sobre cidades médias e sustentáveis, bem como, com a implementação de políticas públicas de 
promoção de sustentabilidade, em conjunto com o estudo do Estatuto da Cidade. Em específico, analisaram-se os indiciadores de caracterização de cidades médias, tais como o tamanho populacional, a economia, o grau de urbanização, a centralidade e a qualidade de vida urbana, a fim de concluir se os municípios de Anápolis e Rio Verde se adequam a tais perfis.

\section{CidAde, CARACTERIZAÇÃo E DiVERSIDADE}

Cidade é uma área onde se agrupam zonas residenciais, comerciais e industriais. A cidade é: "uma área urbanizada, que se diferencia de vilas e outras entidades urbanas através de vários critérios, os quais incluem população, densidade populacional ou estatuto legal"5. A reflexão do conceito de cidade destaca a importância de estudar as áreas verdes como indicadores na avaliação da qualidade ambiental urbana, assim como sendo obrigatórias perante a legislação brasileira, tendo em vista que interferem na boa qualidade de vida da população ${ }^{6}$.

Os espaços urbanos não se restringem a locais de produção industrial ou da troca de mercadorias, eles abrangem edifícios, ruas, postes, placas, árvores, enfim, a produção e a apropriação das relações sociais. Da mesma forma, uma cidade caracteriza-se por um estilo de vida particular dos seus habitantes, pela urbanização, infraestrutura, organização, serviços de transporte, pela concentração de atividades econômicas dos setores secundário e terciário. Uma cidade engloba um núcleo populacional, caracterizado por um espaço amplo onde ocorrem fenômenos sociais, culturais e econômicos.

Em consequência ao surgimento desses núcleos urbanos, impossível não mencionar as funções sociais que apresentam, na medida em que se mostram como desdobramento natural do princípio da função social da propriedade, e como este,

\footnotetext{
${ }^{5}$ Milton Santos. A natureza do espaço. Técnica e tempo. Razão e emoção. 2 ed. (São Paulo: Editora Hucitec, 1997).

${ }^{6}$ Blog Espaço Geografia. Conceito de cidade. Publicado em: 14/04/2008. Acesso em: 19 Jul 2017.
} 
previsto no artigo 182 da Constituição Federal, ${ }^{7}$ pretende se fazer valer por meio das políticas de desenvolvimento urbano.

No entendimento de Garcias e Bernardi, ${ }^{8}$ as funções sociais da cidade podem ser classificadas em três categorias: na primeira, as funções urbanísticas, que têm influenciado no planejamento, na política e na legislação urbana há décadas. Na segunda, estão as funções de cidadania, que englobam os direitos sociais ligados à dignidade da pessoa humana. E por fim, na terceira categoria, destacam-se as funções de gestão, muito relevantes para elucidar as práticas de gestão que são responsáveis pelo bem-estar dos habitantes do meio urbano.

Nessa perspectiva, oportuno mencionar a Carta de Atenas, ${ }^{9}$ documento assinado em 1933 por renomados arquitetos e urbanistas, com o objetivo de orientar o funcionamento e papel do urbanismo na sociedade. Aponta possíveis soluções e projetos para problemas e desafios das cidades. Suas pautas se harmonizam com o que dispõe o Estatuto da Cidade, ao passo em que procura "Conservar a riqueza cultural e a diversidade, construída ao longo da história; conectar-se através de uma variedade de redes funcionais; manter uma fecunda competitividade, porém esforçando-se para a colaboração e cooperação e contribuir para o bem-estar de seus habitantes e usuários". Tal dispositivo, conforme reporta Meirelles, ${ }^{10}$ afirma que as funções sociais da cidade são quatro: habitação, trabalho, circulação e recreação, harmonizando com as propostas elencadas no Estatuto da Cidade.

Na concepção da cidade, a ideia de habitação é essencial. Sem habitantes, a cidade não existe, sendo necessárias moradias fixas. A existência de edificações para habitação apresenta-se como uma das características principais do ambiente urbano. A partir da década de 1960, houve ênfase do tema habitação em razão do aumento de

\footnotetext{
${ }^{7}$ Brasil, Constituição da República Federativa do Brasil: texto constitucional promulgado, em 05 de outubro de 1988. Brasília: Senado Federal, 2017.

${ }^{8}$ Carlos M. Garcias; Jorge Luiz bernardi. "As funções sociais da cidade". In: Revista Direitos Fundamentais \& Democracia.. v. 4 (2008) .7-8.

9 Carta De Atenas. CIAM - Congresso Internacional de Arquitetura Moderna. Disponível em: <http://portal.iphan.gov.br/uploads/ckfinder/arquivos/Carta\%20de\%20Atenas\%201933.pdf>. Acesso em 10 jan. 2018

${ }^{10}$ Hely Lopes Merielles. Direito Municipal Brasileiro. 6ª ed. (São Paulo: Malheiros, 1993)
} 
favelas, que passaram a ser cenário de reduto habitacional da pobreza urbana. A função social se materializa com o acesso à moradia equânime a todos os habitantes. ${ }^{11}$

Importante destacar que o Estatuto da Cidade, ${ }^{12}$ em seu artigo $2^{\circ}$, inciso I, define as funções sociais como garantia do direito à cidade sustentável, entendido como o direito social para as presentes e futuras gerações. Dentre essas funções está o trabalho, a primeira função da Carta de Atenas ${ }^{7}$. Por meio dele que são desenvolvidas atividades fundamentais para a sustentabilidade econômica de uma cidade, sejam a indústria, comércio e serviços.

A terceira função urbanística é a circulação. Trata-se da condição pela qual um fluxo de pessoas e bens se locomove, envolvendo todas as formas de deslocamento dentro do ambiente urbano com o transporte público coletivo e individual, transporte privado motorizado ou não e a pé; e nos modos rodoviário, ferroviário e hidroviário, entre outros. Segundo a Constituição Federal, ${ }^{5}$ em seu artigo 30, inciso V, o transporte é um serviço público de caráter essencial.

Ademais, a recreação ou lazer é outra importante função urbanística da cidade. São espaços que constituem pontos de encontro entre os moradores do ambiente urbano, colaborando com o desenvolvimento saudável das relações interpessoais. Pode-se dizer que atribuir às atividades recreativas o título de função social justifica-se pelo poder da formação de grupos urbanos, o que gera o sentimento de unidade, de solidariedade e de grupo. ${ }^{6}$.

Assim, é de competência dos Municípios, como principal ente federativo na promoção da política urbana, definir como serão desenvolvidas as funções sociais da cidade, utilizando o Estatuto da Cidade como principal instrumento, e especialmente o Plano Diretor, nele previsto. Nesta direção, Milaré ${ }^{13}$ mostra o Plano Diretor como instrumento básico de política urbana, dando os rumos ao desenvolvimento saudável

\footnotetext{
${ }^{11}$ Helion França Moreira. O Plano Diretor e as Funções Sociais Da Cidade. 2008 Disponível em: <http://rigeo.cprm.gov.br/xmlui/bitstream/handle/doc/15713/helion.pdf?sequence=1\&isAllow ed=y>. Acesso em: 09 jan. 2018

${ }^{12}$ Brasil. Estatuto da Cidade: Lei 10.257/2001 que estabelece diretrizes gerais da política urbana. Brasília, Câmara dos Deputados, 2001, 1 a Edição.

${ }^{13}$ Édis Milaré. Direito do Ambiente: a gestão em foco. 6. ed.(São Paulo: RT, 2016)
} 
e sustentável da comunidade municipal. Com sua aprovação e entrada em vigor, o Poder Público municipal teve instrumentos para corrigir uma série de distorções urbanísticas presentes no território do município, algumas delas históricas, além de melhor planejar as ocupações futuras e seus múltiplos usos.

Nessa perspectiva, o Estatuto da Cidade trata sobre o ordenamento das funções sociais da cidade e da propriedade urbana, de forma que se garanta o direito às cidades sustentáveis, compreendendo o direito à terra urbana, à moradia, ao saneamento ambiental e outros, bem como a adoção de medidas compatíveis com os limites da sustentabilidade ambiental.

\section{O QUE SÃO CIDADES MÉDIAS?}

O IBGE elabora conceito sobre cidades médias utilizando o critério populacional, identificando-as como toda cidade "com aglomerações entre 100.000 e 1.000.000 de habitantes". ${ }^{14}$ Contudo, restringir uma cidade média apenas a tal parâmetro é reduzi-la à definição de cidade de "porte médio". No entendimento de Sposito, as cidades médias são aquelas que desempenham papéis de intermediação em suas redes urbanas, diferenciando-as de cidades de "porte médio", definidas unicamente em razão de seu tamanho demográfico. ${ }^{15}$

Nesse mesmo sentido entende o Instituto de Pesquisa Econômica Aplicada, ${ }^{16}$ relatando que "[...] hoje, o peso demográfico de um centro urbano não mais permite qualificar de maneira definitiva e absoluta seu lugar na hierarquia das cidades". Em suma, empregar o parâmetro populacional como único aspecto caracterizador de uma cidade média não é suficiente.

De fato, em razão deste papel intermediador, cada cidade média dispõe de áreas de influência, ou seja, regiões nas quais ela sofre ou exerce interferência.

\footnotetext{
${ }^{14}$ I. S. de França. A cidade média e suas centralidades: O exemplo de Montes Claros no norte de Minas Gerais. 2007. 240f. (Dissertação (Mestrado em Geografia) - Universidade Federal de Uberlândia, Uberlândia.)

${ }^{15} \mathrm{M}$. E. B Sposito. "Desafios para o estudo das cidades médias" In: SEMINÁRIO INTERNACIONAL DE LA RED IBEROAMERICANA DE INVESTIGADORES SOBRE GLOBALIZACIÓN Y TERRITÓRIO, 11, 2010, Mendoza. Anais... Mendoza: UNCUYO - Universidad de Cuyo, 2010. p. 01-18.

${ }^{16}$ Instituto de Pesquisa Econômica Aplicada. Caracterização e tendências da rede urbana no Brasil: redes urbanas regionais - norte, nordeste e centro-oeste. Brasília: IPEA, v.4, 2002.
} 
Conforme o $\mathrm{IBGE}^{17}$, as cidades médias brasileiras e suas respectivas áreas de influência podem ser vistas no mapa a seguir:

Mapa 1: Cidades Médias - Tamanho Populacional e Área De Influência

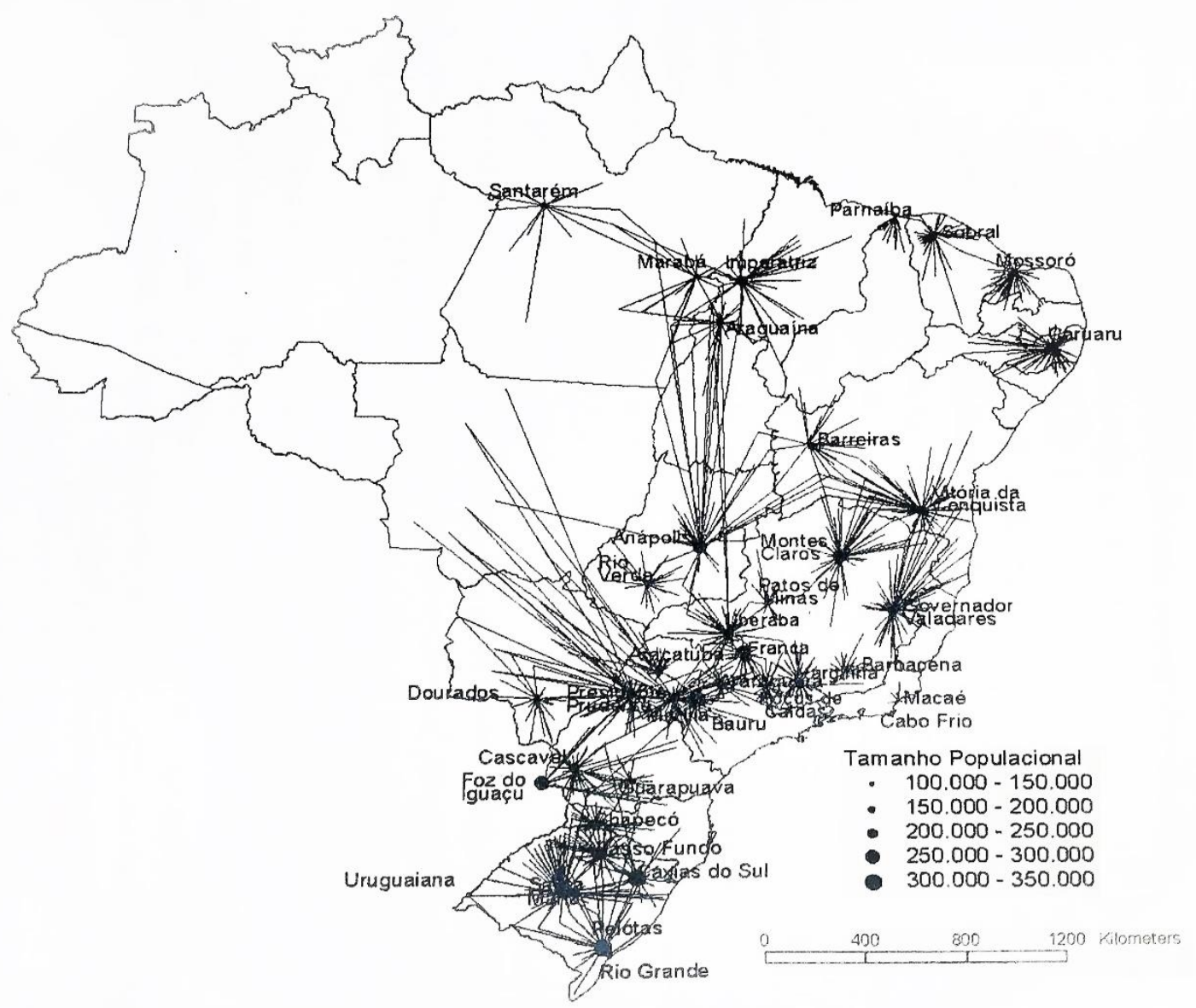

Em suma, as cidades médias são definidas por serem cidades de "médio porte" em razão de sua densidade demográfica, além de atuarem como influenciadoras de regiões adjacentes, conforme as ramificações apresentadas no mapa acima, apontando diversas cidades médias brasileiras e suas áreas de influência.

\section{DESENVOLVIMENTO SUSTENTÁVEL E CIDADE SUSTENTÁVEL}

O termo "sustentabilidade", em seu sentido literal, consiste na capacidade de sustentação de um sistema. Assim, aplicando-se o conceito ao desenvolvimento de uma cidade, remete-se à possibilidade de que seus atributos relativos à fauna, flora, ar e recursos hídricos, sejam mantidos ao longo do tempo, mesmo em face de

\footnotetext{
${ }^{17}$ Instituto Brasileiro de Geografia E Estatística. Regiões de influência das cidades-1993. Rio de Janeiro: IBGE, 2010.
} 
interferências externas a ele. ${ }^{18}$ Logo, a conceituação do termo, no presente contexto, pressupõe, de início, uma relação equilibrada com o ambiente em sua totalidade, na qual os elementos naturais como a fauna e a flora coexistam harmoniosamente com o ser humano e mantenham-se em bom estado de conservação.

Nessa perspectiva, a afirmação do conceito de desenvolvimento sustentável da Comissão Mundial do Meio Ambiente, instituída pela ONU, é aquele que atende as necessidades do presente sem comprometer a habilidade das gerações futuras de atender suas próprias necessidades. ${ }^{19}$ Daí a importância do Estatuto da Cidade que se tornou, depois de promulgado, o principal instrumento de política urbana brasileira. Ele, através de suas diretrizes e propostas, evidenciou a primordialidade de atender as necessidades das gerações humanas, em um ambiente finito de recursos.

Entretanto, não é possível dissociar o desenvolvimento sustentável do desenvolvimento urbano, pois estão ligados de forma direta, de forma que, para o desenvolvimento de uma cidade, é preciso um bom planejamento, que permita atender às necessidades humanas e ao desenvolvimento econômico, respeitando as questões ambientais, para que assim não haja o esgotamento de recursos naturais e ambientais e coloque em risco as futuras gerações.

\section{CidAde Sustentável}

A cidade sustentável é aquela na qual os elementos do meio natural (água, solo, atmosfera, fauna e flora), os elementos do ambiente construído (edificações e infraestruturas construídas em exercício de funções produtivas) e os elementos humanos interagem em conjunto buscando-se a qualidade e duração concomitantes, dos elementos acima expostos.

Conforme a Organização de Governos Locais para a Sustentabilidade - ICLEI: "o conceito de cidade sustentável está orientado para a criação de um habitat

\footnotetext{
${ }^{18}$ HOUAISS. Dicionário eletrônico Houaiss da língua portuguesa. (Rio de Janeiro: Objetiva, 2009).

${ }^{19}$ Nosso Futuro Comum (Relatório Brundtland). Comissão Mundial sobre o Meio Ambiente e Desenvolvimento. (Rio de Janeiro: Editora da Fundação Getúlio Vargas, 1988).
} 
ambientalmente, socialmente e economicamente saudável para a população existente, sem comprometer a mesma possibilidade para as futuras gerações". ${ }^{20}$

Tal proposta exige esforço do Poder Público, das empresas e da população e cujos projetos precisam abarcar todas as vertentes da sustentabilidade, buscando soluções nas esferas ambiental, econômica, política e social. Cidades sustentáveis, portanto, merecem especial atenção por serem, certamente, desafios necessários à manutenção do meio ambiente e do bem-estar social.

As cidades estão em constantes transformações e abrangem as relações interpessoais e efeitos ambientais. Dessa forma, estruturar uma cidade autossustentável exige uma vasta compreensão das relações sociais, serviços, políticas de transporte e geração de energia, bem como seu impacto no ambiente local. Para se criar, efetivamente o desenvolvimento sustentável das cidades, os fatores acima descritos devem estar interligados, e, para haver a cidade sustentável necessário se faz a presença da ecologia urbana, economia e sociologia no planejamento urbano. ${ }^{21}$

Segundo Silva, ${ }^{22}$ existem alguns elementos que servem de parâmetro em um projeto de cidade sustentável, sendo eles: inclusão dos segmentos e interesses coletivos; previsão (incremento de investimentos); e qualidade (elevação da diversidade urbana). A aplicação isolada destes critérios, porém, não é suficiente, deve haver a contribuição da população em razão do interesse em comum do direito ao meio ambiente equilibrado, juntamente com investimentos e a melhoria da qualidade de vida urbana.

Nessa perspectiva, torna-se fundamental a compreensão da importância na mudança do cenário urbano que o Estatuto da Cidade e o Plano Diretor podem proporcionar. Estes dois instrumentos são cruciais no estudo do desenvolvimento sustentável nas cidades médias, em especial os municípios de Anápolis e Rio Verde,

\footnotetext{
${ }^{20}$ Alberto Lopes. Políticas públicas para cidades sustentáveis: Integração intersetorial, federativa e territorial. (Rio de Janeiro: IBAM, MCTI, 2016).

${ }^{21}$ Richard Rogers. Cidades para um pequeno planeta. 1. ed. (São Paulo: Ed. G. Gilili, LTDA, 2012).

${ }^{22}$ Geovany Jessé Alexandre da Silva. Cidades sustentáveis: uma nova condição urbana - Estudo de caso: Cuiabá-MT. (Brasília: Universidade de Brasília, 2011).
} 
objetos de estudo do próximo tópico, pela análise de suas caracterizações quanto ao tamanho, importância regional, qualidade de vida e equipamentos urbanos.

MODELO: CRITÉRIOS PARA CARACTERIZAÇÃO DE CIDADES MÉDIAS E CIDADES SUSTENTÁVEIS.

A aplicação do modelo de cidade média recorrendo aos critérios citados faz-se fundamental para enquadrar um município como cidade média. Este "título" distingue tais cidades de outras ao ponto em que possuem particularidades importantes na construção de um centro urbano sustentável e, consequentemente, com melhor qualidade de vida. As cidades de Anápolis e Rio Verde serão utilizadas como exemplos justamente por conterem as particularidades de cada critério, apresentando características promissoras e possibilidade de um possível desenvolvimento sustentável, constituindo-se em amostras palpáveis de análise.

\section{TAMANHO POPULACIONAL E ECONOMIA}

O município de Anápolis, no último censo realizado em 2010, possuía 334.613 habitantes, com densidade demográfica de 358,58 habitantes por metro quadrado, enquanto a expectativa para 2018 foi de 381.970 pessoas. ${ }^{23}$ Nota-se um aumento na quantidade de habitantes do município de Anápolis, sem que ultrapassasse o limite populacional que o caracteriza uma cidade média, mantendo-se entre 100.000 a 1.000.000 de habitantes.

Acompanhando o crescimento demográfico, também cresceu o Produto Interno Bruto (PIB). Em 2010, o PIB per capita apontou o valor de R\$ 33.013,34, enquanto o de 2015 contou com o montante de R\$ 36.294,20. ${ }^{17}$ Os dados se harmonizam com o fato de Anápolis ser um centro logístico do Centro-Oeste brasileiro, com a economia voltada à indústria de transformação, medicamentos, comércio atacadista e indústria automobilística. Atualmente, o DAIA é a sede do Polo Farmacêutico e Químico Goiano, com mais de 20 empresas, além de possuir uma Estação Aduaneira do Interior (EADI). Fora da área do Distrito Industrial, ainda se

\footnotetext{
${ }^{23}$ IBGE. Instituto Brasileiro de Geografia e Estatística. Panorama. Disponível em: $<$ https://cidades.ibge.gov.br/brasil/go/anapolis/panorama>. Acesso em 10 de jul. de 2018.
} 
contam diversas empresas de porte, tais como AMBEV, Fri-Ribe Rações, Arroz Brejeiro, Friboi, Plumatex, Babioli, Belma Alimentos, Laboratório Uniphar, e Suplemente. $^{24}$

Em relação ao município de Rio Verde, o último censo de 2010 apontou o total de 176.424 habitantes, com densidade demográfica de 21,05 habitantes por metro quadrado, enquanto para 2017 apresenta o montante populacional de 217.048 pessoas, com densidade demográfica de 25,88 habitantes por metro quadrado. ${ }^{25}$ Novamente, considerando o contingente demográfico entre 100.000 a 1.000 .000 de habitantes, a cidade de Rio Verde também se adequa ao indicador que caracteriza uma cidade media no quesito populacional. Da mesma maneira, o Produto Interno Bruto (PIB) per capita de Rio Verde apresentou o valor de RS 25.226,08 no ano de $2010^{26}$. Cinco anos depois, no censo de 2015, apontou um PIB per capita estimado em RS 38.971,32. ${ }^{27}$

\section{GRAU DE URBANIZAÇÃO}

O nível de urbanização é indicador essencial para a caracterização das cidades médias, tendo em vista que o grau de urbanização corresponde à porcentagem das pessoas que residem em sedes de municípios e de distritos independentemente de qualquer consideração sobre suas características geográficas, estruturais ou funcionais, onde qualquer município com mais de $50 \%$ de sua população residente na sede do município é considerado urbano. ${ }^{28}$

\footnotetext{
${ }^{24}$ Prefeitura de Anápolis. Economia. 2018. Disponível em: <http://www.anapolis.go.gov.br/portal/anapolis/economia/>. Acesso em 06 de mar.

${ }^{25}$ Instituto Mauro Borges de Estatísticas e Estudos Socioeconômicos IMB. Estatísticas Municipais - (Séries Históricas). Disponível em: < http://www.imb.go.gov.br/index.php?option=com_content\&view=article\&id=91\&ltemid=219>. Acesso em 03 jan. 2018.

${ }^{26}$ IBGE. Instituto Brasileiro de Geografia e Estatística. Atualização do VAB por município e setor de atividade: serviços, administração pública, indústria, valor impostos e agropecuária em 2012 . Disponível em: <ftp://ftp.ibge.gov.br/Pib_Municipios/2012/base/base_1999_2012_xlsx.zip>. Acesso em 30 out. 2018.

27 IBGE. Instituto Brasileiro de Geografia e Estatística. Panorama. Disponível em: <https://cidades.ibge.gov.br/brasil/go/rio-verde/panorama>. Acesso em 10 de jul. de 2018.

28 José Eli da Veiga. "O Brasil rural ainda não encontrou seu eixo de desenvolvimento". In: Estudos Avançados. Universidade de São Paulo. Instituto de Estudos Avançados. vol. 15, no 43. (São Paulo: IEA, 2001).
} 
Para avaliar o grau de urbanização de determinado município, é preciso examinar fatores como mobilidade urbana, acessibilidade, transporte e circulação quanto à própria estrutura interna da cidade, na perspectiva de transformar a expansão da área central com o surgimento de novas rotas de urbanização. Dentre estes fatores está também a análise dos censos demográficos. Anápolis, seguindo a tendência nacional dos últimos quatro censos, quais sejam, 1980, 1991, 2000 e 2010, apresenta considerável crescimento populacional. ${ }^{19}$

Em Rio Verde, o grau de urbanização também apresentou notável crescimento, seguindo a tendência nacional dos mesmos últimos quatro censos demográficos. Informações do site Atlas do Desenvolvimento Humano no Brasil mostram que "entre 1991 e 2000, a população do município cresceu a uma taxa média anual de 2,95\%". Em Goiás, esta taxa foi de 2,46\%, e no Brasil foi de 1,63\%, no mesmo período. Em porcentagem, "a taxa de urbanização do município passou de 87,87\% para $91,01 \% " .29$

\section{CENTRALiDADE}

Anápolis é notadamente um município com localização privilegiada, tendo em vista se situar no centro do estado de Goiás e se interligando com outros municípios do referido estado e com o restante do país. Localiza-se a 55 km de Goiânia e a 154 km de Brasília, além do fácil acesso rodoviário ao Porto Seco do Centro-Oeste, o qual dispõe de ramal ferroviário. Tanto é que recebe o "apelido" de "Trevo do Brasil", justamente pela facilidade de integração aos demais centros consumidores do país, o que se desdobra em uma vantagem econômica salutar. ${ }^{30}$

Ainda, o município está ligado com os estados de Minas Gerais, São Paulo, Espirito Santo, pela ferrovia Centro-Atlântica. Por esta estrada se transportam produtos do Distrito Agroindustrial de Anápolis - DAIA. Outro fator crucial é a ferrovia Norte-Sul, ainda em implantação e que possui seu marco zero exatamente em

\footnotetext{
29 Atlas Do Desenvolvimento Humano Brasileiro. Perfil. Rio Verde, GO. Disponível em: <http://www.atlasbrasil.org.br/2013/pt/perfil_m/rio-verde_go>. Acesso em 30 out. 2018.

30 Instituto Mauro Borges. Segplan. Governo de Goiás. Disponível em: <www.imb.go.gov.br/perfilweb/estatistica bde.asp $>$. Acesso em: 10 jan. 2018.
} 
Anápolis e se conectará a ferroaria Centro-Atlântica, ramal da Rede Ferroviária Federal S/A (RFFSA), que integra o corredor de exportação Goiás-Minas-GeraisEspirito Santo, interligado à Estação Aduaneira do Interior (EADI) ou Porto Seco do Centro-Oeste. ${ }^{31}$

Avançando para a análise da centralidade em Rio Verde, a autora Gislene Margaret Avelar Guimarães ${ }^{32}$ afirma que "o município tem uma localização privilegiada em relação à distância de Goiânia, Brasília, Uberlândia e São Paulo. É cortado por duas rodovias federais (BR-060 e BR 452) e uma estadual (GO-174), que serve de escoamento da produção para o Porto de São Simão (Hidrovia ParanaíbaTietê-Paraná)". Desde o início da construção da ferrovia norte-sul, a cidade de Rio Verde objetiva juntamente com a gestão municipal facilitar e dinamizar o processo de exportação e importação, possibilitando a geração de emprego e renda para o município e desburocratizando processos ligados à logística.

\section{QUALIDADE DE VIDA URBANA}

As cidades médias continuam mantendo a sua importância econômica e demográfica na rede urbana do Brasil. Nos últimos anos, as cidades médias foram aquelas que apresentaram tanto o maior crescimento do PIB quanto o crescimento populacional mais acentuado. Sem embargo, as cidades médias também apresentaram um crescimento do PIB per capita, ou seja, o avanço foi em um ritmo superior ao crescimento da população. ${ }^{12}$

O crescimento dessas cidades tem ligação com a garantia da sadia qualidade de vida, vez que quanto mais a cidade cresce, em termos populacionais e econômicos, é necessário o investimento em infraestrutura urbana para garantir aos habitantes,

\footnotetext{
${ }^{31}$ Maria de Faria Amaral Brito. A EVOLUÇÃO E PRODUÇÃO DA ESTRUTURA URBANA EM ANÁPOLIS - 1993 A 2004: estudo da interferência das gestões municipais. (Dissertação (Formação Regional: Política, Economia e Cultura). Universidade Federal de Goiás - UFG. Instituto de Estudos Socioambientais. Goiânia-GO, 2007).

32 Gislene Margaret Alevar Guimarães. AGRONEGÓCIO, DESENVOLVIMENTO E SUSTENTATIBLIDADE: UM ESTUDO DE CASO EM RIO VERDE - GO. (Tese (Ciências Ambientais). Universidade Federal de Goiás - Programa de Doutorado em Ciências Ambientais da UFG. Goiânia-GO, 2010).
} 
saúde, educação, meio de transporte, lazer, esporte, saneamento básico, moradia, segurança e o incentivo da preservação do meio ambiente.

O munícipio de Anápolis possui vários projetos incentivadores do esporte e bem-estar, como a corrida de rua, que se realiza de forma bimestral no munícipio, várias quadras de esportes e academias para os idosos, instalados em praças de bairros da cidade. Oferece também transporte coletivo a população, o qual ainda está sendo ampliado para atender a todos, de forma rápida e eficiente. Por fim, destaca-se que o município, revela-se tendente a melhorar a sadia qualidade de vida urbana, implantando parques ambientais, tais como, Parque Ambiental Ipiranga, Parque da Cidade, Parque da Liberdade e Parque JK, dentre outros.

Também se verifica o destaque que o município de Rio Verde/GO possui no quesito qualidade de vida, buscando oferecer infraestrutura adequada, visando à saúde e bem-estar da população. Ademais, a cidade se destaca no que tange a instalação de instituições de capacitação de mão-de-obra, assim como o número de matriculados na educação profissional, podendo ser comparada ao munícipio de Anápolis/GO. Ou seja, a mão-de-obra local está se preparando melhor para atender à demanda dos novos empreendimentos agroindustriais instalados no município. ${ }^{23}$

\section{COMPARAÇÃO DE DUAS CIDADES REGIONAIS}

A caracterização de uma cidade como sendo média pode ser feita utilizando os critérios acima discutidos - tamanho populacional, economia, grau de urbanização e qualidade de vida urbana. Para tanto, utilizar-se-á as cidades de Anápolis e Rio Verde, as adequando ao modelo composto por tais critérios. Ao passo em que se amoldem aos critérios será possível chamá-las de cidades médias. Para tanto, imprescindível compreender aspectos basilares dos municípios de Anápolis e Rio Verde.

\section{BREVE APRESENTAÇÃO DAS CIDADES DE ANÁPOLIS E RIO VERDE}

A cidade de Anápolis se destaca no contexto regional por diversos traços, como sua dinâmica econômica e localização estratégica, sendo o município portador 
de condições naturais propícias ao plantio e demais atividades agropecuárias. Sua posição estratégica é um dos fatores que a classifica como uma cidade média. A melhoria das vias de transportes, tais como, ferroviais, novas rodovias, aeroportos de cargas, ampliou mais a circulação de bens e de pessoas, transformando Anápolis centro intermediário de comércio, sendo coletor e exportador de gêneros agropecuários de área primária e redistribuidor de bens manufaturados. ${ }^{33}$

Sua evolução histórica contribuiu para que a cidade seja destaque como um dos municípios do estado de Goiás, com notável crescimento populacional e econômico, advindo da indústria e do comércio. Sua posição geográfica faz dela um centro de atenções das grandes multinacionais. Em razão do crescimento populacional e econômico, Anápolis "requer estratégias de desenvolvimento sustentável de forma a garantir a sadia qualidade de vida das pessoas que aqui residem e a proteção e preservação do meio ambiente". ${ }^{34}$

Por seu turno, a cidade de Rio Verde destaca-se na agropecuária. Além disso, o município estimula o crescimento de novas empresas e grandes indústrias sem abandonar a atividade que deu início à sua história de sucesso, moderna e inovadora. Rio Verde se destaca em relação a outras cidades porque está em emergente crescimento, por possuir infraestrutura para acolher empresas e pessoas que chegam à busca de novas oportunidades.

Atualmente, Rio Verde é mais do que uma grande cidade de Goiás, é um polo econômico que cresce junto com o Brasil. O aumento da quantidade de empresas na região de Rio Verde ocasionou o aumento no número de ofertas de emprego. Desde então, o município se apresenta como centro migratório, visto que ao enorme grupo

\footnotetext{
33 J. Polonial. Ensaio sobre a história de Anápolis. Anápolis: AEE, 2000.

${ }^{34}$ Gabriel Anibal Santos de Oliveira. "A POLÍTICA HABITACIONAL NO BRASIL DESDE A CRIAÇÃO DO SISTEMA FINANCEIRO DA HABITAÇÃO ATÉ O PROGRAMA MINHA CASA MINHA VIDA, EM CIDADES MÉDIAS: um estudo preliminar sobre Santa Cruz do Sul - RS". In: VIII Seminário Internacional sobre Desenvolvimento Regional, 9 a 11, 2015. Rio Grande do Sul. Programa de Pós-Graduação Desenvolvimento Regional. Santa Cruz do Sul, 2015. Disponível em: <https://online.unisc.br/acadnet/anais/index.php/sidr/article/viewFile/13319/2485>. Acesso em 10 jan. 2018.
} 
de pessoas atraídas por melhores oportunidades. ${ }^{35}$ Logo, Rio Verde se caracteriza como uma cidade do agronegócio e pode ser considerada cidade média, por ser capaz de desenvolver novas funções que alteram rapidamente sua realidade e estrutura, podendo, inclusive, integrar em sua organização as diretrizes para a construção de cidades sustentáveis. Para melhor compreensão, seguem os mapas das duas cidades analisadas, no escopo de visualizar seu tamanho territorial, uma em relação à outra e ao Estado de Goiás.

\section{LOCALIZAÇÃO E TAMANHO DAS CIDADES DE ANÁPOLIS E RIO VERDE NO ESTADO DE GOIÁS}

Mapa 2: Localização e tamanho do município de Anápolis.

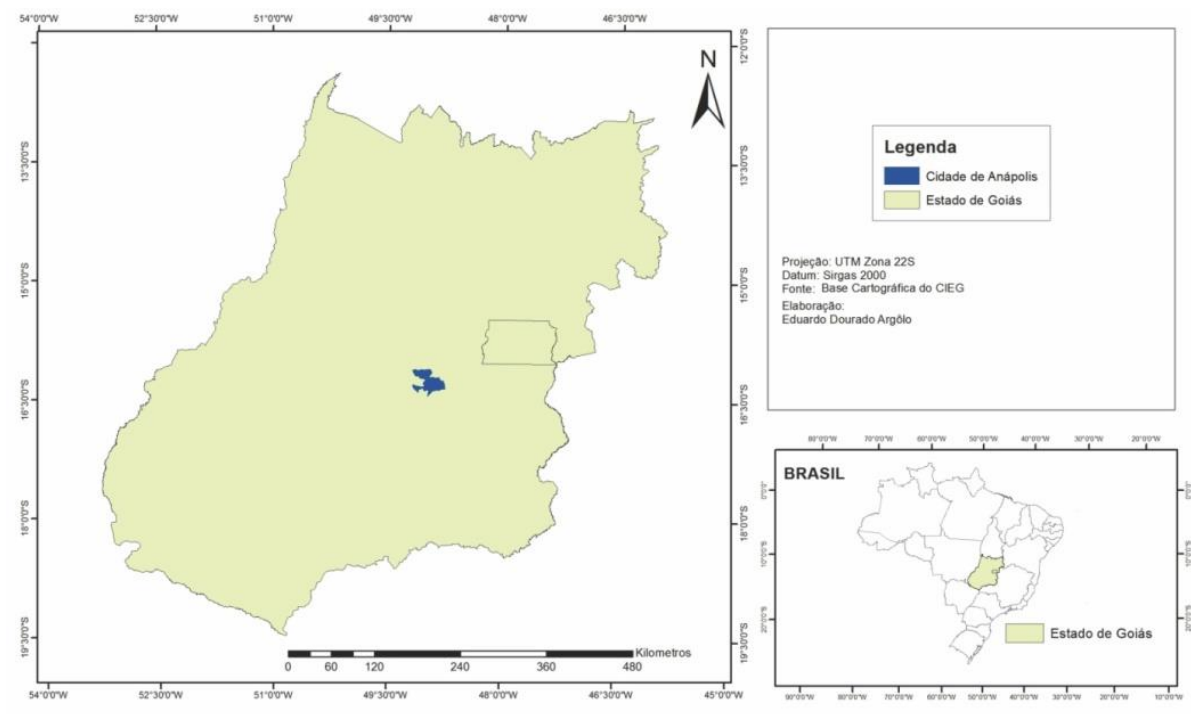

Elaboração: Eduardo Dourado Argolo

\footnotetext{
${ }^{35}$ Haihani Silva Passos. Zoneamento urbano de Rio Verde: uma proposta para ordenamento e uso do solo. Goiânia, 2010.

Disponível

em:

<https://www.google.com.br/url?sa=t\&rct=j\&q=\&esrc=s\&source=web\&cd=4\&cad=rja\&uact=8\&ved=0ahUKEwicha2M88r WAhXHg5AKHZjiCHgQFgg1MAM\&url=http\%3A\%2F\%2Fwww.unialfa.com.br\%2Flib\%2Fdownload.php\%3Farq\%3Darqs \%2Fbiblioteca\%2Fdigital\%2F25.pdf\%26nome\%3Dzoneamento-urbano-de-rio-verde-uma-proposta-para-ordenamentodo-uso-do-solo.pdf\&usg=AFQjCNHQJN77khCXfSjf4NxqNKiNgRJV0Q>. Acesso em: 29 de set. 2017.
} 
Mapa 3: Localização e tamanho do município de Rio Verde.
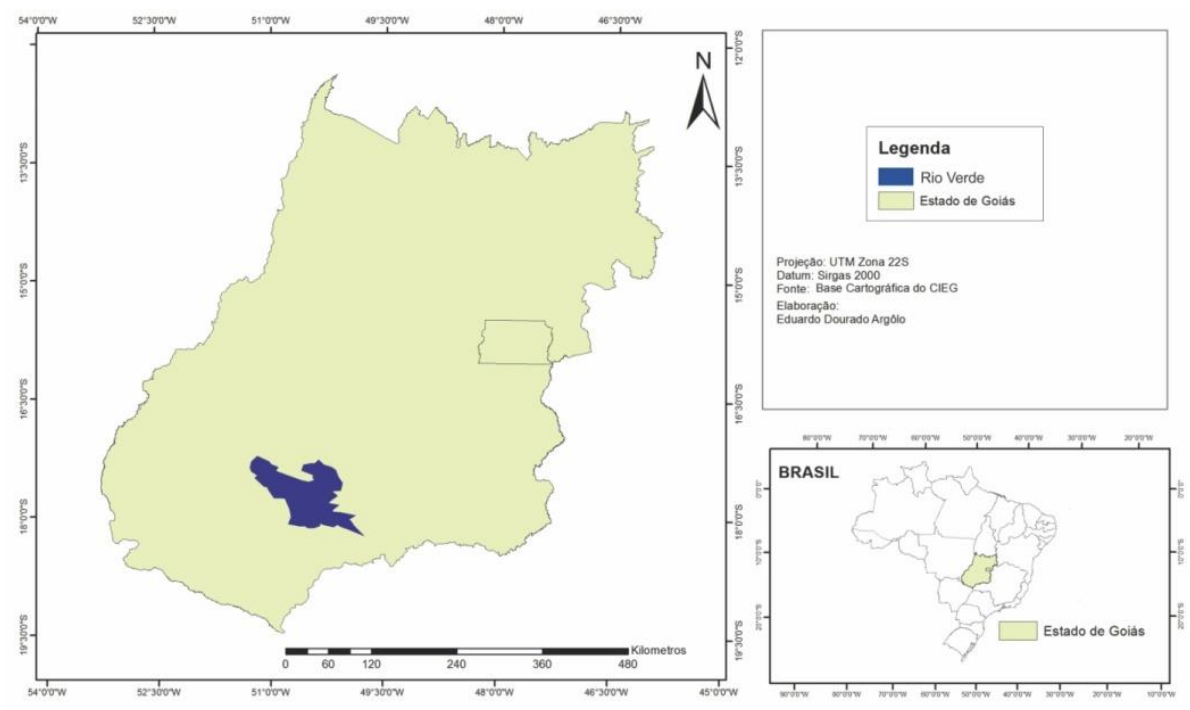

Elaboração: Eduardo Dourado Argolo

Em suma, é possível estabelecer um comparativo entre as duas cidades seguindo o modelo proposto de caracterização das cidades médias. Para tanto, os critérios referentes ao tamanho populacional, economia, grau de urbanização, centralidade e qualidade de vida serão utilizados para nortear a delimitação de ambos os municípios, aqui utilizados como modelo, as inserindo no cenário nacional como cidades médias. No entanto, antes da utilização deste modelo é preciso estabelecer um paralelo entre ambas cidades estudadas e pesquisadas.

APLICAÇÃO DO MODELO DE CARACTERIZAÇÃO DE CIDADES MÉDIAS AOS MUNICÍPIOS DE ANÁPOLIS E RIO VERDE.

O modelo de caracterização de cidades médias e sustentáveis - análise dos critérios: grau de urbanização, economia, centralidade, qualidade e vida e tamanho populacional dos municípios de Anápolis e Rio Verde - foi aplicado nos municípios retromencionados. Este modelo foi testado por meio de visitas às referidas cidades, onde se procurou coletar dados estatísticos e informações nas secretárias do meio ambiente, educação e de saúde, bem como acesso a sites de coleta de dados, tais 
como, Instituto Brasileiro de Geografia e Estatística (IBGE) ${ }^{14}$ e Instituto Mauro Borges (IMB). ${ }^{23}$

Dessa forma, buscou-se a aplicação do modelo de caracterização, aplicando-o nos municípios de Anápolis e Rio Verde, a fim de verificar se os municípios se enquadram como cidades médias e sustentáveis. Por meio dos resultados obtidos, foram desenvolvidos quadros comparativos para cada indicador analisado, como se mostra a seguir:

TAMANHO POPULACIONAL

\begin{tabular}{|c|c|c|c|}
\hline \multirow{2}{*}{ Municípios } & \multicolumn{3}{|c|}{ População (hab.) } \\
\cline { 2 - 4 } & Censo 2000 & Censo 2010 & Estimativa 2017 \\
\hline Anápolis & 288.085 & 334.613 & 375.142 \\
\hline Rio Verde & 116.552 & 176.424 & 217.048 \\
\hline
\end{tabular}

Fonte: IBGE Elaboração: autora

O processo de urbanização das cidades médias acima apresentadas é guiado pelo setor industrial com participação relevante das atividades relacionadas ao setor de serviços. A descentralização rural estabelecida no país a partir da Constituição de 1988 conduziu estes municípios a uma mudança no conteúdo das políticas públicas de desenvolvimento urbano em âmbito institucional e legal nas três esferas de governo. ${ }^{36}$ As tabelas demonstram que os dois municípios comparados tiveram crescimento populacional nos últimos anos, sendo que a cidade de Anápolis possui maior quantidade de habitantes.

ECONOMIA

\begin{tabular}{|c|c|c|}
\hline Cidades & Anápolis & Rio Verde \\
\hline Economia & PIB percapita $=34.282(2014)$ & PIB percapita $=36.539,06(2013)$ \\
\hline
\end{tabular}

Fonte: Prefeitura de Anápolis e Rio Verde. Elaborado pela autora.

\footnotetext{
${ }^{36}$ Brasil. Estatuto da Cidade: Lei 10.257/2001 que estabelece diretrizes gerais da política urbana. Brasília, Câmara dos Deputados, 2001, 1a Edição.
} 
Em que pese à cidade de Anápolis possuir maior número de habitantes, percebe-se que a cidade de Rio Verde tem PIB per capita maior, ou seja, a movimentação de bens e serviços por seus habitantes é superior à de Anápolis.

\section{CEnTRALidADE}

\begin{tabular}{|c|c|c|}
\hline Cidades & Anápolis & Rio Verde \\
\hline & BR 060 & BR 060 \\
Centralidade & BR414 & BR452 \\
& BR153 & GO174 \\
\hline
\end{tabular}

Fonte: Prefeitura de Anápolis e Rio Verde. Elaborado pela autora.

As duas cidades são beneficiadas pela centralidade, pois estão em localidades estratégicas, uma vez que se ligam às principais rodovias federais e estaduais, favorecendo a importação e exportação de produtos e serviços de forma mais rápida e econômica do que outras localidades do país, beneficiando a economia local. Contudo, pela sua localização e histórica condição no apoio ao desenvolvimento do Norte goiano e ocupação do Vale de São Patrício, Anápolis tem sido chamada de "cidade trevo". 37

\section{GRAU DE URBANIZAÇÃO}

\begin{tabular}{|c|c|c|c|c|c|c|c|c|c|c|}
\hline \multirow{2}{*}{ ANO } & \multicolumn{4}{|c|}{ População de Anápolis } & \multicolumn{5}{c|}{ População Rio Verde } \\
\cline { 2 - 12 } & TOTAL & Urbana & \% & Rural & \% & TOTAL & Urbana & \% & Rural & \% \\
\hline $\mathbf{1 9 9 1}$ & 239,38 & 226,93 & $94,80 \%$ & 12,453 & $5,20 \%$ & 96,309 & 84,142 & $87,37 \%$ & 12,167 & $12,63 \%$ \\
\hline $\mathbf{2 0 0 0}$ & 288,09 & 280,16 & $97,25 \%$ & 7,921 & $2,75 \%$ & 116,55 & 106,079 & $91,01 \%$ & 10,473 & $8,99 \%$ \\
\hline $\mathbf{2 0 1 0}$ & 334,61 & 328,76 & $98,25 \%$ & 5,858 & $1,75 \%$ & 176,42 & 163,54 & $92,70 \%$ & 12,884 & $7,30 \%$ \\
\hline
\end{tabular}

Fonte: IBGE Elaboração: autora

Os dados mostram que o processo de urbanização das duas cidades gerou aumento no número de habitantes na rede urbana, mantendo-se maior do que a população de zona rural. Ademais, em comparação, verificou-se que a população rural de Rio Verde é proporcionalmente maior do que a de Anápolis, e isto se deve em razão da atividade econômica exercida.

\footnotetext{
${ }^{37}$ Francisco Itami Campos. Ciência política: Introdução à Teoria do Estado. (Goiânia: Vieira, 2009).
} 
O processo de urbanização das cidades médias acima apresentadas é guiado pelo setor industrial com participação relevante das atividades relacionadas ao setor de serviços. A descentralização rural estabelecida no país a partir da Constituição de 1988 conduziu estes municípios a uma mudança no conteúdo das políticas públicas de desenvolvimento urbano em âmbito institucional e legal nas três esferas de governo. ${ }^{12}$ As tabelas demonstram que os dois municípios comparados tiveram crescimento populacional nos últimos anos, sendo que a cidade de Anápolis possui maior quantidade de habitantes.

QUALIDADE DE VIDA

\begin{tabular}{|c|c|c|c|c|}
\hline QUALIDADE DE VIDA & Anápolis & Quantidade & Rio Verde & Quantidade \\
\hline Transporte Público & Sim & 01 & Sim & 01 \\
\hline PSF (Postos de Saúde) & Sim & 36 & Sim & 21 \\
\hline UPA - Unidades de Pronto Atendimento & Sim & 01 & Sim & 01 \\
\hline Hospitais Públicos & Sim & 05 & Sim & 04 \\
\hline Escolas Municipais & Sim & 60 & Sim & 35 \\
\hline Escolas Públicas na Zona Rural & Sim & 68 & Sim & 112 \\
\hline Bairros com redes de esgoto & Sim & 255 & Sim & 108 \\
\hline Parques & Sim & 07 & Sim & 07 \\
\hline
\end{tabular}

Fonte: Prefeitura de Anápolis e Rio Verde. Elaborado pela autora.

No quesito qualidade de vida, verifica-se que dos 139 bairros de Rio Verde, 108 contam com rede de esgoto, perfazendo o total de 77,7\%. ${ }^{38}$ Por sua vez, dos 275 bairros de Anápolis, o total de 255 constam com rede de esgoto, ou seja, 92,72\%. ${ }^{39}$ Dados da prefeitura de Rio Verde informam que o município conta com o tratamento de $100 \%$ do esgoto captado, sendo que o mesmo número se aplica para Anápolis, segundo levantamento do Sistema Nacional de Informações sobre Saneamento $(\mathrm{SNIS})^{40}$.

\footnotetext{
${ }^{38} \mathrm{MBI}$. Rio Verde (GO) - Índice de bairros e demais núcleos populacionais. Disponível em: <https://www.mbi.com.br/mbi/biblioteca/cidade/rio-verde-go-br/>. Acesso em 20 out. 2018.

${ }^{39} \mathrm{MBI}$. Anápolis (GO) - Índice de bairros e demais núcleos populacionais. Disponível em: <https://www.mbi.com.br/mbi/biblioteca/cidade/anapolis-go-br/>. Acesso em 20 out. 2018.

40 Índice de tratamento de esgoto: Veja percentual tratado em relação ao coletado por cidade do Brasil - ANÁPOLIS, GO. Disponível em: <http://www.deepask.com/goes?page=anapolis/GO-Indice-de-tratamento-de-esgoto:-Veja-opercentual-tratado-em-relacao-ao-total-coletado-na-sua-cidade>. Acesso em 23 out. 2018.
} 
Em relação aos outros critérios, PSF (postos de saúde), UPA - Unidade de Pronto Atendimento, Hospitais Públicos e conveniados com o SUS, Escolas Públicas Municipais, em comparação com a diferença em número de habitantes, verifica-se que Rio Verde, mesmo possuindo menos escolas públicas de ensino fundamental e menos postos de saúde, aparenta um resultado positivo mais patente e visível do que Anápolis.

Vale ressaltar que a existência de alguns dos serviços elencados, por si só, não garante sua boa qualidade. No entanto, discutir se os hospitais ou escolas públicas prestam um serviço de qualidade envolve outros fatores como o correto direcionamento de verbas públicas, capacitação profissional e infraestrutura adequada. O objetivo central da pesquisa não é aprofundar nesses fatores, e sim tecer uma crítica sobre a melhoria dos serviços, uma vez já implementados nas cidades discutidas.

Não obstante, dados do site Atlas do Desenvolvimento Humano no Brasil comparam o Índice de Desenvolvimento Humano (IDHM) ao longo dos anos dos municípios brasileiros, conforme as tabelas a seguir:

\begin{tabular}{|l|l|l|l|}
\hline \multicolumn{4}{|c|}{ Índice de Desenvolvimento Humano Municipal e seus componentes } \\
Município - Anápolis - GO & \multicolumn{1}{|c|}{ - } \\
\hline \multicolumn{1}{|c|}{ IDHM e componentes } & $\mathbf{1 9 9 1}$ & $\mathbf{2 0 0 0}$ & $\mathbf{2 0 1 0}$ \\
\hline IDHM Educação & 0,320 & 0,491 & 0,660 \\
\hline \% de 18 anos ou mais com fundamental completo & 34,65 & 42,52 & 60,88 \\
\hline \% de 5 a 6 anos na escola & 40,03 & 74,41 & 71,35 \\
\hline $\begin{array}{l}\text { \% de 11 a 13 anos nos anos finais do fundamental } \\
\text { REGULAR SERIADO ou com fundamental completo }\end{array}$ & 45,74 & 72,42 & 86,93 \\
\hline \% de 15 a 17 anos com fundamental completo & & & \\
\hline \% de 18 a 20 anos com médio completo & 24,06 & 40,68 & 67,09 \\
\hline IDHM Longevidade & 13,32 & 23,26 & 49,53 \\
\hline Esperança de vida ao nascer & 0,670 & 0,776 & 0,822 \\
\hline IDHM Renda & 65,18 & 71,54 & 74,33 \\
\hline Renda per capita & 0,650 & 0,691 & 0,737 \\
\hline
\end{tabular}

Fonte: PNUD, IPEA e FJP 


\begin{tabular}{|l|c|c|c|}
\hline \multicolumn{3}{|c|}{$\begin{array}{c}\text { Índice de Desenvolvimento Humano Municipal e seus componentes } \\
\text { Municipio - Rio Verde - GO }\end{array}$} \\
\hline \multicolumn{1}{|c|}{ IDHM e componentes } & 1991 & 2000 & 2010 \\
\hline IDHM Educação & 0,265 & 0,444 & 0,656 \\
\hline \% de 18 anos ou mais com fundamental completo & 26,22 & 37,37 & 55,58 \\
\hline \% de 5 a 6 anos na escola & 39,77 & 66,10 & 87,21 \\
\hline $\begin{array}{l}\text { \% de 11 a 13 anos nos anos finais do fundamental REGULAR } \\
\text { SERIADO ou com fundamental completo }\end{array}$ & 36,04 & 61,30 & 86,64 \\
\hline \% de 15 a 17 anos com fundamental completo & & \\
\hline \% de 18 a 20 anos com médio completo & 16,77 & 43,43 & 66,00 \\
\hline IDHM Longevidade & 14,02 & 22,49 & 45,37 \\
\hline Esperança de vida ao nascer & 0,687 & 0,802 & 0,853 \\
\hline IDHM Renda & 66,24 & 73,13 & 76,17 \\
\hline Renda per capita & 0,638 & 0,713 & 0,765 \\
\hline
\end{tabular}

Fonte: PNUD, IPEA e FJP

Em análise, a cidade de Anápolis teve uma taxa de crescimento de 42,28\% em seu IDHM entre 1991 e 2010. Ainda, a dimensão cujo índice mais cresceu em termos absolutos foi Educação (com crescimento de 0,340), seguida por Longevidade e por Renda. ${ }^{41}$ Em verificação similar, o município de Rio Verde, entre 1991 e 2010, teve taxa de crescimento de 54,51\% no IDHM. Assim como Anápolis, a dimensão cujo índice mais cresceu em termos absolutos foi Educação (com crescimento de 0,391), seguida por Longevidade e por Renda. ${ }^{25}$

CRITÉRIOS DE ANÁLISE NA CARACTERIZAÇÃO DE UMA CIDADE COMO SENDO MÉDIA, UTILIZANDO COMO EXEMPLO OS MUNICÍPIOS DE ANÁPOLIS E RIO VERDE.

Utilizando como molde de análise os municípios de Anápolis e Rio Verde e após a verificação de todos os critérios essenciais a ser apreciados para determinar se uma cidade se encaixa da definição de "média" ou não, é possível condensar as informações até então apresentadas na elaboração de um modelo. A proposta é que este modelo sirva de matriz para a verificação se demais cidades brasileiras se adequam à "condição" de cidade média. A tabela a seguir serve como um guia para o exame proposto.

\footnotetext{
41 Atlas do Desenvolvimento Humano Brasileiro. Perfil. Anápolis, GO. Disponível em: <http://www.atlasbrasil.org.br/2013/pt/perfil_m/anapolis_go>. Acesso em 30 out. 2018.
} 


\begin{tabular}{|l|l|l|}
\hline \multicolumn{2}{|c|}{ MODELO } \\
\hline \multicolumn{1}{|c|}{ Critérios } & \multicolumn{1}{|c|}{ Anápolis } & \multicolumn{1}{c|}{ Rio Verde } \\
\hline Tamanho populacional & $\begin{array}{l}\text { Aumentou 16,15\% em 10 anos } \\
\text { (censos de 2000 e 2010) }\end{array}$ & $\begin{array}{l}\text { Aumentou 51,36\% em 10 anos (censos de } \\
\text { 2000 e 2010) }\end{array}$ \\
\hline Economia (PIB per capita) & $\begin{array}{l}\text { Aumentou 9,93\% em cinco } \\
\text { anos (censos de 2010 e 2015) }\end{array}$ & $\begin{array}{l}\text { Aumentou 54,48\% em cinco anos (censos } \\
\text { de 2010 e 2015) }\end{array}$ \\
\hline \multirow{3}{*}{ Grau de Urbanização } & $\begin{array}{l}\text { Em 19 anos a população } \\
\text { urbana aumentou 44,87\% e } \\
\text { população rural diminuiu } \\
\text { 53\% (censos de 1991 e 2010) }\end{array}$ & $\begin{array}{l}\text { Em 19 anos a população urbana } \\
\text { aumentou 94,36\% e população rural } \\
\text { também aumentou em 5,9\% (censos de } \\
\text { 1991 e 2010) }\end{array}$ \\
\hline Centralidade & $\begin{array}{l}\text { Por ela passam três rodovias } \\
\text { nacionais }\end{array}$ & $\begin{array}{l}\text { Por ela passam duas rodovias nacionais e } \\
\text { uma estadual }\end{array}$ \\
\hline Qualidade de Vida (IDHM) & $\begin{array}{l}\text { Crescimento de 42,28\% nos } \\
\text { últimos 19 anos (censos de } \\
\text { Crescimento de 54,51\% nos últimos 19 } 19\end{array}$ & $\begin{array}{l}\text { anos (censos de 1991 e 2010) } \\
\text { 19910) }\end{array}$ \\
\hline
\end{tabular}

É possível observar que houve crescimento no indicador de tamanho populacional, sendo que em Rio Verde, a porcentagem foi significativamente menor que em Anápolis, pelo fato de que esta já possuía quantidade mais elevada de habitantes do que aquela. O mesmo ocorre da análise do PIB per capita, critério diretamente ligado ao crescimento econômico. Quanto ao grau de urbanização, nota um aumento pequeno na população rural de Rio Verde, em comparação com a população urbana. Tal aumento é justificado ao considerar o crescimento no negócio agropecuário da região. O critério centralidade revela que os dois municípios estão em regiões que favorecem o fluxo de pessoas e mercadorias, atraindo indústrias, favorecendo o desenvolvimento econômico. Por fim, influenciam também no Índice de Desenvolvimento Humano Municipal, com crescimento expressivo nas duas cidades.

Em síntese, ao se aplicar os dados de uma cidade no modelo elaborado, e o resultado demonstrar crescimento nos indicadores economia, urbanização e qualidade de vida, possuir um número de habitantes dentre o parâmetro já estabelecido e contar com uma posição estratégica que lhe confira centralidade, pode-se dizer que a cidade em análise é considerada cidade média.

A relevância de tal constatação reside na consciência do potencial que um município detém. As possibilidades de crescimento no âmbito econômico, social, de infraestrutura e principalmente econômico são consideravelmente maiores do que cidades que não apresentam as mesmas características. Além disso, o potencial de 
implementação de políticas sustentáveis é substancialmente maior do que outras cidades que não se encaixam neste perfil. E a construção de um futuro onde o desenvolvimento econômico, social e ambiental possa coexistir deve ser o agente motivador dessas ações.

\section{CONSIDERAÇÕES FINAIS}

A importância da pesquisa feita reside em visualizar os critérios para a caracterização de uma cidade como cidade média a partir da análise exemplo das cidades de Anápolis e Rio Verde, no estado de Goiás. Além disso, é relevante compreender o potencial presente em tais cidades, justamente em decorrência de suas peculiares características. Seu tamanho médio, aliado ao recente crescimento industrial, dá forma a um ambiente propício para implementar práticas voltadas à melhoria da qualidade de vida em todos os aspectos, especialmente no que tange à consolidação de um desenvolvimento sustentável.

O modelo de cidade sustentável busca conciliar os elementos naturais com os do ambiente construído, no intuito de que coexistam em harmonia, com um equilíbrio gerador de desenvolvimento econômico aliado à sadia e melhor qualidade de vida. A cidade média é ambiente favorável para a prática de um desenvolvimento sustentável em que seja viável reduzir os impactos ambientais ocasionados pela atividade industrial, sem prejudicar o seu funcionamento.

Os municípios utilizados para a concretização do estudo são as cidades de Anápolis e Rio Verde, cidades médias. Possuem potencial na consolidação de melhor qualidade de vida, porém, ainda é longo o caminho para que sejam chamadas de "sustentáveis". Ademais, os referidos municípios só contam com 1 (uma) unidade de pronto atendimento (UPA), para atender a toda população.

Portanto, em análise, é possível concluir que, Anápolis e Rio Verde possuem destaque no desenvolvimento da economia e do setor social, além da existência de serviços essenciais na construção de melhor qualidade de vida de seus habitantes. As medidas adotadas não são suficientes para caracterizá-las como cidades sustentáveis, tendo em vista que ainda não adotam práticas eficientes de sustentabilidade 
ambiental, pois precisam aprimorar diversos ramos, como o setor de saneamento básico que não abrange todos os bairros, e também, no que se refere à saúde pública, a população está desamparada pelo sistema ser insuficiente.

Por fim, Anápolis e Rio Verde são cidades médias, que adotam práticas de sustentabilidade ambiental e são exemplos para demais municípios. Entretanto, as medidas praticadas não são suficientes para caracterizá-las como cidades sustentáveis, tendo em vista que ainda não adotam práticas eficientes de sustentabilidade ambiental, pois precisam aprimorar diversos ramos. Em suma, o Poder Público Municipal ainda tem um grande caminho de implantação e execução de ações e projetos ambientais, até se tornarem cidades totalmente sustentáveis.

\section{REFERENCIAS}

Alberto Lopes. Políticas públicas para cidades sustentáveis: Integração intersetorial, federativa e territorial. (Rio de Janeiro: IBAM, MCTI, 2016).

${ }^{1}$ Atlas do Desenvolvimento Humano Brasileiro. Perfil. Anápolis, GO. Disponível em: <http://www.atlasbrasil.org.br/2013/pt/perfil_m/anapolis_go>. Acesso em 30 out. 2018.

Atlas Do Desenvolvimento Humano Brasileiro. Perfil. Rio Verde, GO. Disponível em: <http://www.atlasbrasil.org.br/2013/pt/perfil_m/rio-verde_go>. Acesso em 30 out. 2018.

Blog Espaço Geografia. Conceito de cidade. Publicado em: 14/04/2008. Acesso em: 19 Jul 2017.

Brasil, Constituição da República Federativa do Brasil: texto constitucional promulgado, em 05 de outubro de 1988. Brasília: Senado Federal, 2017.

Brasil. Estatuto da Cidade: Lei 10.257/2001 que estabelece diretrizes gerais da política urbana. Brasília, Câmara dos Deputados, 2001, 1a Edição.

Brasil. Estatuto da Cidade: Lei 10.257/2001 que estabelece diretrizes gerais da política urbana. Brasília, Câmara dos Deputados, 2001, 1a Edição.

Carlos M. Garcias; Jorge Luiz bernardi. "As funções sociais da cidade". In: Revista Direitos Fundamentais E Democracia.. v. 4 (2008) .7-8.

Carta De Atenas. CIAM - Congresso Internacional de Arquitetura Moderna. Disponível em: 
<http://portal.iphan.gov.br/uploads/ckfinder/arquivos/Carta\%20de\%20Atenas\%20 1933.pdf>. Acesso em 10 jan. 2018

Édis Milaré. Direito do Ambiente: a gestão em foco. 6. ed.(São Paulo: RT, 2016)

Francisco Itami Campos. Ciência política: Introdução à Teoria do Estado. (Goiânia: Vieira, 2009).

Gabriel Anibal Santos de Oliveira. "A POLÍTICA HABITACIONAL NO BRASIL DESDE A CRIAÇÃO DO SISTEMA FINANCEIRO DA HABITAÇÃO ATÉ O PROGRAMA MINHA CASA MINHA VIDA, EM CIDADES MÉDIAS: um estudo preliminar sobre Santa Cruz do Sul - RS". In: VIII Seminário Internacional sobre Desenvolvimento Regional, 9 a 11, 2015. Rio Grande do Sul. Programa de Pós-Graduação Desenvolvimento Regional. Santa Cruz do Sul, 2015. Disponível em: $<$ https://online.unisc.br/acadnet/anais/index.php/sidr/article/viewFile/13319/24 85>. Acesso em 10 jan. 2018.

Geovany Jessé Alexandre da Silva. Cidades sustentáveis: uma nova condição urbana Estudo de caso: Cuiabá-MT. (Brasília: Universidade de Brasília, 2011).

Gislene Margaret Alevar Guimarães. AGRONEGÓCIO, DESENVOLVIMENTO E SUSTENTATIBLIDADE: UM ESTUDO DE CASO EM RIO VERDE - GO. (Tese (Ciências Ambientais). Universidade Federal de Goiás - Programa de Doutorado em Ciências Ambientais da UFG. Goiânia-GO, 2010).

Haihani Silva Passos. Zoneamento urbano de Rio Verde: uma proposta para ordenamento e uso do solo. Goiânia, 2010. Disponível em: $<$ https://www.google.com.br/url?sa=t\&rct=j\&q=\&esrc=s\&source=web\&cd=4\&cad=rj a\&uact $=8 \&$ ved $=0$ ahUKEwicha2M88rWAhXHg5AKHZjiCHgQFgg1MAM\&url=http\%3A\%2 F\%2Fwww.unialfa.com.br\%2Flib\%2Fdownload.php\%3Farq\%3Darqs\%2Fbiblioteca\%2F digital\%2F25.pdf\%26nome\%3Dzoneamento-urbano-de-rio-verde-uma-propostapara-ordenamento-do-uso-dosolo.pdf\&usg=AFQjCNHQJN77khCXfSjf4NxqNKiNgRJV0Q>. Acesso em: 29 de set. 2017.

Helion França Moreira. O Plano Diretor e as Funções Sociais Da Cidade. 2008 Disponível em: <http://rigeo.cprm.gov.br/xmlui/bitstream/handle/doc/15713/helion.pdf?sequenc $\mathrm{e}=1 \&$ isAllow ed=y>. Acesso em: 09 jan. 2018

Hely Lopes Merielles. Direito Municipal Brasileiro. $6^{a}$ ed. (São Paulo: Malheiros, 1993)

HOUAISS. Dicionário eletrônico Houaiss da língua portuguesa. (Rio de Janeiro: Objetiva, 2009).

I. S. de França. A cidade média e suas centralidades: O exemplo de Montes Claros no norte de Minas Gerais. 2007. 240f. (Dissertação (Mestrado em Geografia) Universidade Federal de Uberlândia, Uberlândia.) 
IBGE. Instituto Brasileiro de Geografia e Estatística. Atualização do VAB por município $e$ setor de atividade: serviços, administração pública, indústria, valor impostos $e$ agropecuária em 2012. Disponível em: <ftp://ftp.ibge.gov.br/Pib_Municipios/2012/base/base_1999_2012_xlsx.zip>. Acesso em 30 out. 2018.

IBGE. Instituto Brasileiro de Geografia e Estatística. Panorama. Disponível em: <https://cidades.ibge.gov.br/brasil/go/anapolis/panorama>. Acesso em 10 de jul. de 2018.

IBGE. Instituto Brasileiro de Geografia e Estatística. Panorama. Disponível em: $<$ https://cidades.ibge.gov.br/brasil/go/rio-verde/panorama>. Acesso em 10 de jul. de 2018 .

Índice de tratamento de esgoto: Veja percentual tratado em relação ao coletado por cidade do Brasil - ANÁPOLIS, GO. Disponível em: <http://www.deepask.com/goes?page=anapolis /GO-Indice-de-tratamento-deesgoto:-Veja-o-percentual-tratado-em-relacao-ao-total-coletado-na-sua-cidade>. Acesso em 23 out. 2018.

Instituto Brasileiro de Geografia E Estatística. Regiões de influência das cidades-1993. Rio de Janeiro: IBGE, 2010.

Instituto de Pesquisa Econômica Aplicada. Caracterização e tendências da rede urbana no Brasil: redes urbanas regionais - norte, nordeste e centro-oeste. Brasília: IPEA, v.4, 2002.

Instituto Mauro Borges de Estatísticas e Estudos Socioeconômicos IMB. Estatísticas Municipais - $\quad$ (Séries Históricas). Disponível em: < http://www.imb.go.gov.br/index.php?option=com_content\&view=article\&id=91\&Ite mid=219>. Acesso em 03 jan. 2018.

Instituto Mauro Borges. Segplan. Governo de Goiás. Disponível em: <www.imb.go.gov.br/perfilweb/estatistica bde.asp>. Acesso em: 10 jan. 2018.

J. Polonial. Ensaio sobre a história de Anápolis. Anápolis: AEE, 2000.

José Eli da Veiga. "O Brasil rural ainda não encontrou seu eixo de desenvolvimento". In: Estudos Avançados. Universidade de São Paulo. Instituto de Estudos Avançados. vol. 15, nº 43. (São Paulo: IEA, 2001).

M. E. B Sposito. "Desafios para o estudo das cidades médias" In: SEMINÁRIO INTERNACIONAL DE LA RED IBEROAMERICANA DE INVESTIGADORES SOBRE GLOBALIZACIÓN Y TERRITÓRIO, 11, 2010, Mendoza. Anais... Mendoza: UNCUYO Universidad de Cuyo, 2010. p. 01-18.

Maria de Faria Amaral Brito. A EVOLUÇÃO E PRODUÇÃO DA ESTRUTURA URBANA EM ANÁPOLIS - 1993 A 2004: estudo da interferência das gestões municipais. 
(Dissertação (Formação Regional: Política, Economia e Cultura). Universidade Federal de Goiás - UFG. Instituto de Estudos Socioambientais. Goiânia-GO, 2007).

MBI. Anápolis (GO) - Índice de bairros e demais núcleos populacionais. Disponível em: <https://www.mbi.com.br/mbi/biblioteca/cidade/anapolis-go-br/>. Acesso em 20 out. 2018.

MBI. Rio Verde (GO) - Índice de bairros e demais núcleos populacionais. Disponível em: <https://www.mbi.com.br/mbi/biblioteca/cidade/rio-verde-go-br/>. Acesso em 20 out. 2018.

Milton Santos. A natureza do espaço. Técnica e tempo. Razão e emoção. 2 ed. (São Paulo: Editora Hucitec, 1997).

Nosso Futuro Comum (Relatório Brundtland). Comissão Mundial sobre o Meio Ambiente e Desenvolvimento. (Rio de Janeiro: Editora da Fundação Getúlio Vargas, 1988).

Prefeitura de Anápolis. Economia. 2018. Disponível em: $<$ http://www.anapolis.go.gov.br/portal/anapolis/economia/>. Acesso em $06 \mathrm{de}$ mar.

Richard Rogers. Cidades para um pequeno planeta. 1. ed. (São Paulo: Ed. G. Gilili, LTDA, 2012). 


\title{
Medium Cities and Environmental Sustainability: Characterization and Regional Performance
}

\begin{abstract}
This article intends to discuss the average cities from the perspective of environmental sustainability, discussing the social function of the city and how its application lacks a strong urban policy. It exposes considerations about medium-sized cities, highlighting singularities in relation to metropolises and small towns. It is conceptualized sustainable development, locating it in the Statute of the City to glimpse the so-called sustainable city. Seeks the application of the proposed model in the municipalities of Rio Verde and Anápolis. The methodology used is bibliographical, and the method adopted is comparative, analyzing data on the municipalities of Goiás, obtained from the Brazilian Institute of Geography and Statistics/IBGE, the Mauro Borges Institute and the respective municipal municipalities. The selected municipalities are medium-sized cities that need to adopt more punctual actions to be considered sustainable, such as, improving basic sanitation, selective collection of solid waste, and other sustainable urban development options.
\end{abstract}

Keywords: Medium cities. Sustainability. Urban Politic. 